\title{
TERRAPLENAGEM NA CONSTRUÇÃO CIVIL
}

\author{
Otavio Galego
}

Gerson de Marco

\begin{abstract}
Resumo: Nesse estudo, serão abordadas as técnicas utilizadas atualmente no serviço de terraplenagem, ou movimento de terra como também é chamado. Suas etapas, maquinários necessários, planejamento visando reduzir custos, e toda sua definição de modo geral. Terraplenagem define-se pelo ato ou efeito de terraplenar um terreno para que o mesmo fique plano, permitindo assim as próximas etapas da construção. A terraplenagem é primordial, e de extrema importância no ramo da engenharia civil, não sendo possível executar pavimentação e edificação de grandes obras, por exemplo, sem a execução dessa etapa. Exige planejamento adequado, elaboração de cálculos e gráficos, para que sejam feitos os cortes e aterros necessários, com a finalidade de aplanar o terreno evitando o bota fora de restos de terra ou entulhos.
\end{abstract}

Palavras-chave: Classificação de solos. Compactação. Escavação. Equipamentos. Rodovias. Terraplenagem.

\section{WORKPLACE SAFETY IN CIVIL CONSTRUCTION}

Abstract: Abstract: In this study, will be approached the techniques currently used in the earthmoving service, or land movement as it is also called. Its steps, necessary machinery, planning to reduce costs, and all its definition in general. Earthmoving is defined by the act to the effect of embankment a land so that it is flat, thus allowing the next stages of construction. Earthworks are of paramount importance and extremely important in the field of civil engineering, and it is not possible to carry out paving and building major works, for example without carrying out this stage. It requires proper planning, calculation and graphing, so that the necessary cuts and embankments are made in order to flatten the ground by avoiding the boot out of debris or debris.

Key-words: Soil classification. Compaction. Excavation. Equipment. Highways. Earthmoving. 


\section{INTRODUÇÃO}

Neste trabalho, serão abordadas todas as etapas de terraplenagem, demonstrando o passo a passo realizado atualmente, principalmente em rodovias, com base nos estudos disponíveis de docentes e Engenheiros, tais como a Professora Jisela Aparecida Satanna Grecco, o Eng. Douglas Fadul Villibor, e o professor Gil Carvalho Paulo de Almeida. Também contém informações consideráveis dos manuais de normas e implantação do DER e DNER, e mais um estudo apropriado do José Tadeu Balbo. Essas informações em conjunto trazem ao conhecimento popular, qual é o processo mais adequado, rentável e utilizado por empresas de terraplenagem.

Nos dias de hoje, o processo de pavimentação se tornou muito mais ágil, devido os equipamentos atuais, e tornando possível a construção de grandes rodovias dentro de prazos pré-estabelecidos, trazendo benefícios e facilidade de locomoção para a população em geral.

Para gerar uma rodovia é indispensável o processo de terraplenagem, que tem início no desmatamento, e finaliza-se na compactação total do solo.

Antes que o trabalho comece a ser executado no terreno, é necessário um planejamento, tendo em vista que a terra exposta não sofra com a ação do tempo e efeitos da chuva, evitando erosões e contaminações, ou outros efeitos ambientais.

$\mathrm{O}$ corte e o aterro são etapas de terraplenagem, sendo o corte a retirada da terra excedente no terreno, e o aterro a colocação dessa terra onde ela se encontra escassa. È possível a necessidade de empréstimo de terra de locais próximos, para ocupar o espaço escasso, possibilitando assim o nivelamento do local a ser pavimentado. Essa movimentação de terra deve ser calculada de tal forma que as escavações e os volumes retirados sejam aproveitados ao máximo, evitando assim o bota fora.

O primeiro estágio, após o corte e aterro, é o espalhamento do solo, em uma camada com no máximo $30 \mathrm{~cm}$ (trinta centímetros) de espessura. A seguir é feita a compactação do solo, onde se utilizam grandes rolos mecânicos, e deve ser executada em curto prazo, para que o material espalhado não seja transportado pela ação da chuva. Antes do trabalho das máquinas pesadas, é importante que as valetas dos topos dos taludes estejam prontas, isso impede que a água da chuva desça pelo corte. Desta maneira é feita toda a preparação para receber a pavimentação asfáltica das rodovias.

É correto afirmar que, para todo tipo de obra, no ramo da Engenharia Civil, o movimento de terra é necessário, pois nos terrenos naturais sempre haverá desníveis e vegetação de grande porte ou rasteira, que devem ser retiradas para que a obra siga seu cronograma, sem eventuais problemas. Assim como a necessidade da classificação de solos é indispensável para o início de uma obra, pois o terreno receberá esforços e cargas diferentes, que devem ser suportadas e descarregadas nesse solo, sem que haja qualquer danificação da estrutura já erguida. Pode ser necessária a preparação e manipulação desse solo previamente, para que o mesmo suporte o peso da edificação, e também através da classificação de solos, será determinado o tipo de fundação utilizada, tudo isso visando primeiramente à segurança da construção e economia, e para evitar futuros imprevistos na estrutura.

O planejamento é a base fundamental para a realização de qualquer obra, nele serão listadas todas as etapas, em sequência correta, para que a construção ou pavimentação seja duradoura e segura, para seus usuários em particular ou para a população como um todo, se tratando de obras do governo. 


\section{REVISÃO BIBLIOGRÁFICA}

\section{Conceito Terraplenagem}

Situa-se a compactação e nivelamento de acordo com a necessidade do relevo do terreno antes da execução de uma obra a ser realizada. Define-se por terraplenagem o ato de encher de terra os vãos de um terreno, que consiste em uma técnica usada no âmbito da construção civil. Relacionando com os processos de aplanar ou alisar um terreno, trabalho muito usado em rodovias, aeroporto, prédios, ferrovias e outras construções. Para cada tipo de relevo a um método a ser utilizado, de acordo com a classificação do terreno e seu desnível. Para que posamos analisar a compactação com vista de cálculos, custos e as maquinas apropriadas para o trabalho a ser executado.

O rendimento da terraplenagem manual é muito mais baixo que o rendimento da mecanizada, significando lentidão nos trabalhos. Manualmente esse processo dependia de mão-de-obra brutalmente barata e animais para transporte, e era feito com equipamentos como pás, picaretas e carroças ou vagonetas, como afirma a professora Jisela Aparecida Santanna Grecco, em seu estudo. Com o avanço da tecnologia a mãode-obra foi se tornando cada vez mais escassa, e por consequência mais cara, inviabilizando seu uso para grandes construções. O maquinário mecanizado ainda tinha alto custo, porém uma única escavadeira executava o trabalho de até cem homens, tornando vantajosa sua aquisição, sendo assim a terraplenagem manual, nos dias de hoje, tem baixo uso, principalmente para obras de grandes proporções.

Ainda com base no estudo (apostila) da professora Jisela Aparecida Santanna Grecco, podemos dizer que a terraplenagem mecanizada surgiu em consequência da escassez e encarecimento de mão-de-obra, e devido à eficiência dos equipamentos, trazendo alta produtividade e com isso uma concorrência no preço do serviço.

Atualmente, as grandes obras como rodovias e grandes construções exigem o uso de equipamentos modernos, sendo cada um com seu uso específico. Exemplo: tratores de lâmina, moto-scrapers, escavadeiras, perfuratriz e compressores para a escavação de solos e rochas. Também são usados retroescavadeiras, carregadeiras e caminhões para extração e transporte dos materiais. Motoniveladoras, caminhão tanque e grade de disco para espalhamento, umidecimento, mistura e homogenização de solos. A compactação é feita através de trator compactador, rolo de pneu e rolo liso vibratório. E para os serviços auxiliares de pavimentação, são utilizados os tratores de pneus e as retroescavadeiras, dados do manual de Implatação Básica do DNER (1996). Os motores movidos a biodisel agridem menos a atmosfera, e hoje são bastante utilizados, pois as empresas de grande porte principalmente buscam recursos de forma a prevenir a degradação do meio ambiente como um todo. São várias as empresas existentes no mercado competitivo que dispõe dessa consciência ambiental.

A seguir, cinco figuras de maquinas, que são utilizadas atualmente no processo de terraplenagem mecanizado. (Figura 1 Motoniveladora, figura 2 Pá carregadeira, figura 3 Rolo compressor liso, figura 4 Caminhão tanque e figura 5 Rolo compactador pé de carneiro): 


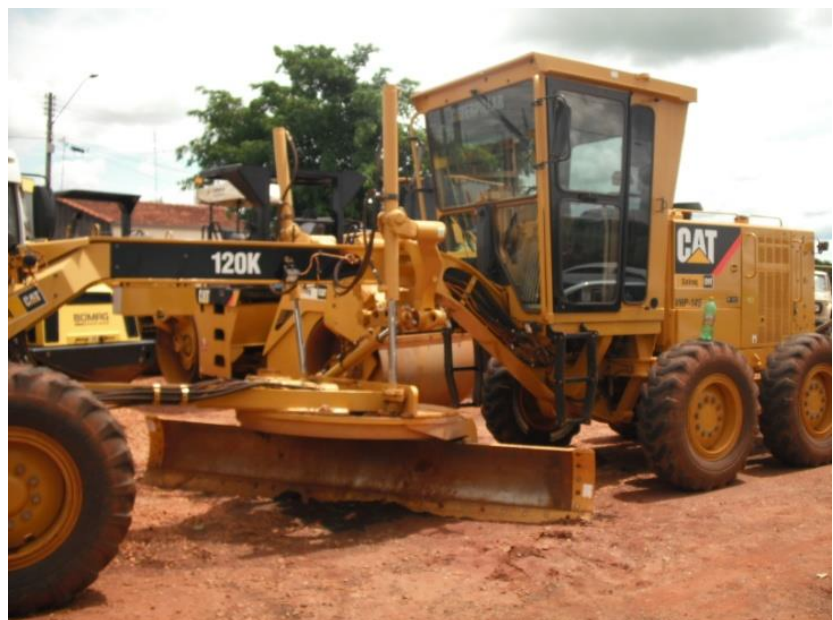

Figura 1 - Motoniveladora

Fonte: Pavisolo Geotécnica e Pavimentação LTDA

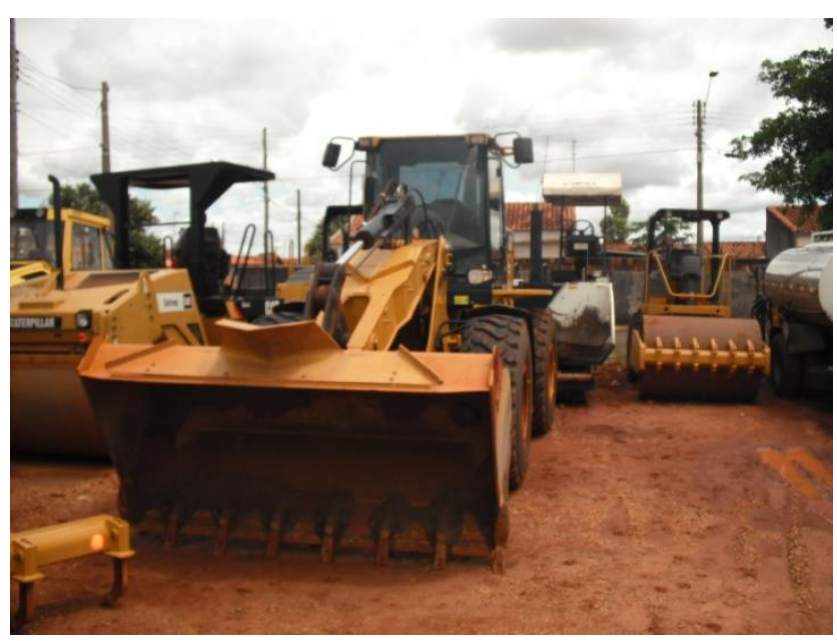

Figura 2 - Pá carregadeira

Fonte: Pavisolo Geotécnica e Pavimentação LTDA

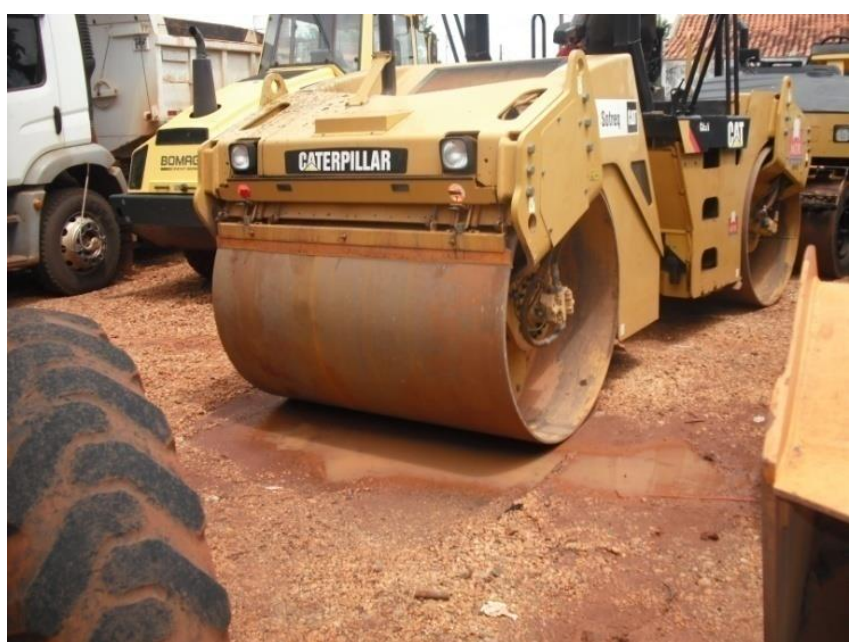

Figura 3 - Rolo compactador liso

Fonte: Pavisolo Geotécnica e Pavimentação LTDA 


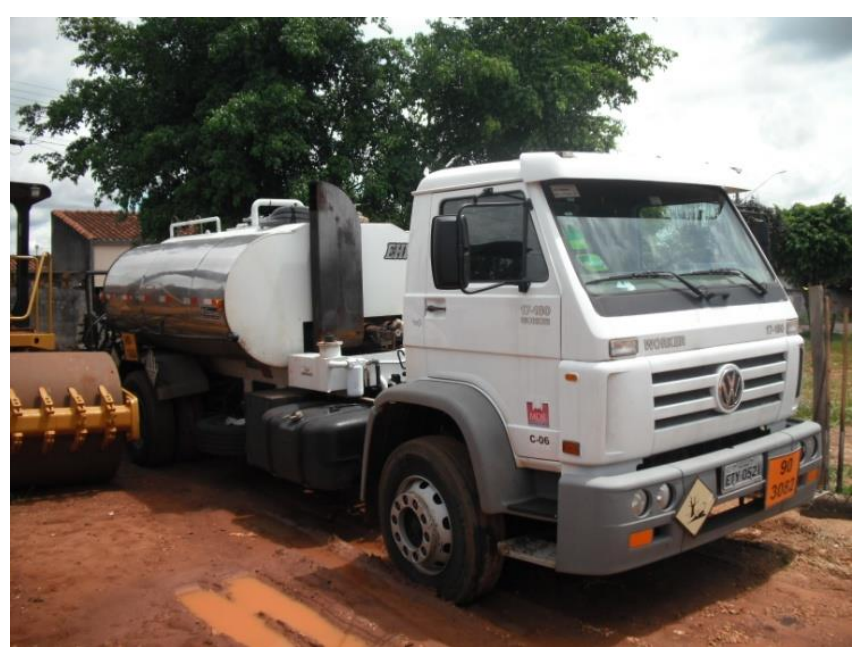

Figura 4 - Caminhão tanque/pipa

Fonte: Pavisolo Geotécnica e Pavimentação LTDA

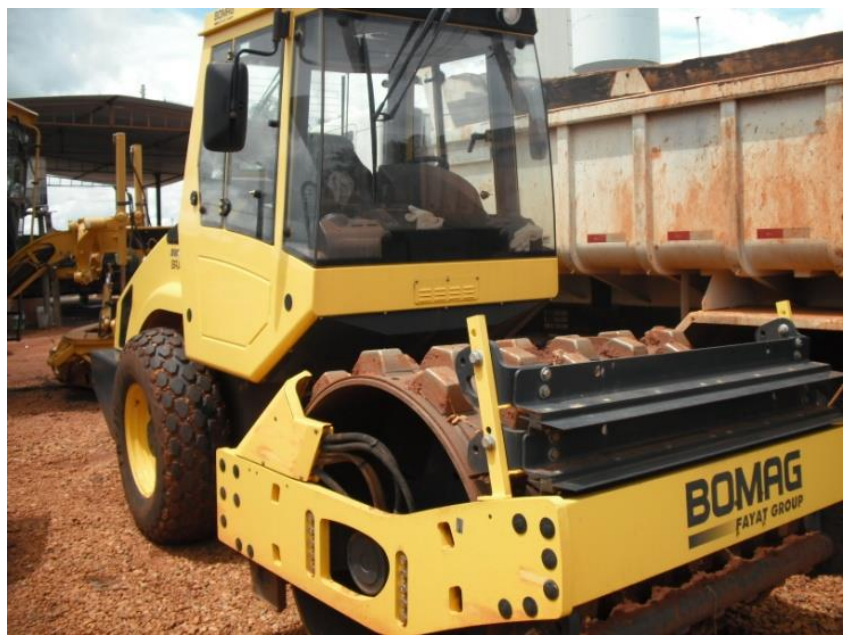

Figura 5 - Rolo Compactador pé-de-carneiro

Fonte: Pavisolo Geotécnica e Pavimentação LTDA

\subsection{Classificação de Solos}

Segundo ao prof. Gil Carvalho Paulo de Almeida, conforme cita em sua apostila Construção de Estradas II (página 34), os solos são classificados geralmente em três grupos, sendo granulares, coesivos e orgânicos,

- Granulares: São solos compostos por pedras, pedregulhos, cascalhos e areias, ou seja, são solos compostos por grandes partículas. Estas misturas, individualmente soltas, no estado seco, não se aderem uma à outra, tornando altamente permeáveis.

- Coesivos: Os espaços vazios entre as suas partículas são muito pequenos, formando uma estrutura resistente a penetração de água, fazendo com que a 
mesma seja absorvida de forma lentamente. Porém uma vez que tenha sido penetrada no solo, a água é dificilmente extraída de seu interior.

- Orgânicos: São compostos de matéria orgânica, ou seja, são formados através da decomposição vegetal, animal e de microorganismos.

A classificação de solos é necessária para o processo de terraplenagem, pois irá verificar os materiais do solo e definir quais tipos de equipamentos deverão ser utilizados para sua compactação, garantindo estabilização do terreno de maneira segura. E também é importante para o processo de construção/pavimentação, onde serão definidos os tipos de fundações implantadas, de forma a absorver o impacto e as cargas que esse solo irá receber ao longo do tempo.

\subsubsection{Estabilização Granulométrica}

É necessário verificar a necessidade de estabilizar o solo, alterando qualquer propriedade do mesmo, com a finalidade de aumentar sua resistência, melhorando seu comportamento sob o ponto de vista da Engenharia Civil. Essa estabilização consiste em adicionar um elemento, denominado estabilizante, para melhorar suas propriedades geotécnicas. Isso aumenta a resistência á deformação, reduz à compressibilidade e a sensibilidade a ação de variações externas, principalmente a umidade, e também serve para reduzir ou aumentar a permeabilidade do solo. Esses dados foram listados na apostila do Engenheiro Douglas Fadul Villibor, da cidade de São Carlos (1978), onde detalha o procedimento de estabilização granulométrica ou mecânica. Ele deixa claro que para um solo estável é necessário uma granulometria bem proporcionada de material grosso, podendo conter certa dose de ligante argiloso. A estabilização granulométrica tem sua maior aplicação na área de estradas e pavimentos. O limite de liquidez (a umidade como a qual o solo se comporta como material plástico) e o limite de plasticidade (capacidade dos solos de serem moldados, sob certas condições de umidade, sem variação de volume), também são definidos e analisados para maior estabilidade do solo.

\subsection{Escavação e Limpeza}

A etapa de terraplenagem tem início no desmatamento, que é a retirada da vegetação de grande porte existente no terreno, juntamente com a limpeza que se trata da retirada da vegetação rasteira e a retirada da camada vegetal, solo que contém ainda matéria orgânica.

No caso de rodovias, o desmatamento da faixa de domínio deve ser o suficiente para garantir a isolação e as operações de construção e visibilidade dos motoristas, com precaução de não expor os solos e os taludes naturais a erosão, facilitando o assoreamento e a sobrecarga dos sistemas de drenagem, segundo ao Manual de Implantação Básica do DNER (1996). A camada vegetal deverá ser estocada, ela será usada futuramente para a recomposição vegetal de taludes de corte e aterros. Cuidados especiais precisam ser tomados nos bota-foras de solo vegetal, pois eles podem ser facilmente levados pela chuva, prejudicando o meio ambiente. O desmatamento deverá ser definido após um planejamento, onde serão previstos os limites necessários á implantação de cortes e aterros, denominados off-sets de terraplenagem. É comum que esses limites pré-definidos sofram alterações durante a fase de implantação, devido a dificuldade das máquinas de acompanhar a linha sinuosa que limita os off-sets. Em vista disso para facilitar o 
desempenho operacional, o desmatamento passa a ser feito por segmentos de reta, aumentando a área a ser desmatada, isso agride o meio ambiente e facilita a erosão e assoreamento, e diminui a estabilidade dos taludes. Uma solução a esse problema foi citada pelo DNER (1996), que seria o desmatamento manual sem destocamento, em faixa que não exceda as demarcações implantadas, pois existe a facilidade de operar as máquinas nesses limites de desmatamento e também a de executar a obra de acordo com o projeto, gerando um contorno de fácil identificação e acompanhamento pela equipe mecânica.

\subsubsection{Empréstimos e Bota-fora}

Os empréstimos de terra são necessários quando o volume do corte não preenche a escassez do aterro, eles são obtidos pela escavação do terreno natural perpendicular ao eixo da futura rodovia com acumulo de material sobre a plataforma projetada, dessa forma o custo com transporte de longa distancia é anulado. Este ato permite que se formem "piscinas", ao longo da rodovia, isso gera proliferação de doenças e a formação de taludes altíssimos, compostos pela soma das alturas do aterro construído e caixa de empréstimo. Por esse motivo precisam ser criados sistemas de drenagem de modo que evite a erosão do solo e ravinamento de grande porte, prevenindo danos à população.

Cuidados especiais também devem ser tomados com relação aos bota-foras. Em geral, o planejamento prévio das escavações já tem o objetivo de evitar os desperdícios com material excedente, que após os preenchimentos dos aterros serão descartados, eles não deverão ser depositados nas bocas dos cortes ou sobre talvegues sem qualquer compactação, provocando em consequiência a erosão e levando ao assoreamento da rede de drenagem, reduzindo a vazão, extinguindo a vegetação e sujando os mananciais, prejudicando a fauna de espécies aquática, e gerando a proliferação de insetos transmissores de doenças. $\mathrm{O}$ ideal no caso de excesso de material seria o alargamento de aterros, reduzindo a inclinação de taludes e mesmo construindo plataformas continuas á estrada.

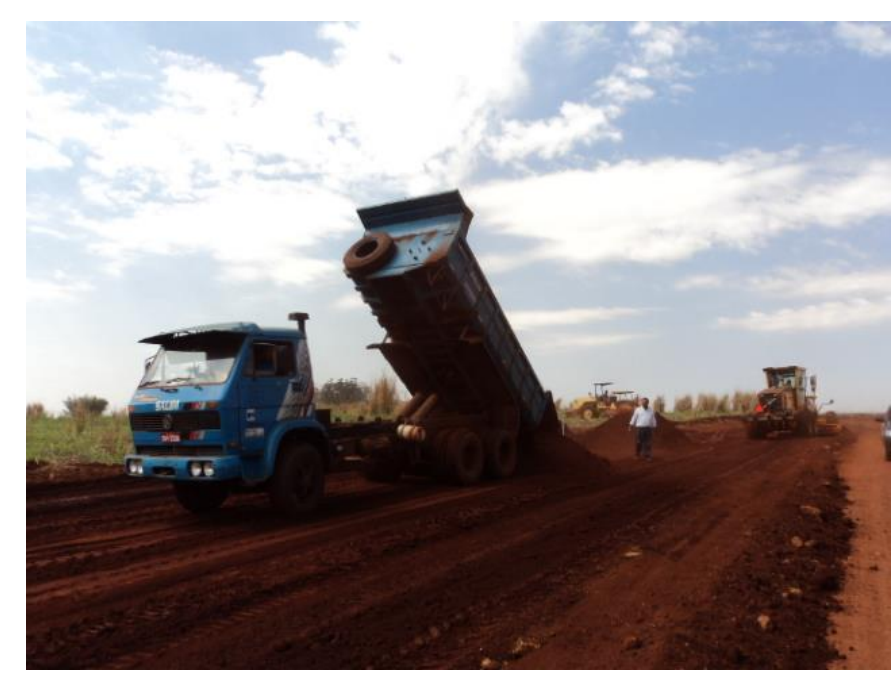

Figura 6 - Empréstimos de terra / aterro

Fonte: Pavisolo Geotécnica e Pavimentação LTDA

1 Graduando em Eng. Civil Otavio Galego

2 Orientador, docente Prof. Especialista Gerson de Marco 


\subsection{Compactação}

A compactação é um processo mecânico, onde se obtêm uma maior resistência do solo, cedo foi utilizada para melhorar as propriedades do solo em contacto com a água e possibilitar a circulação sobre os caminhos percorridos por tráfego animal e pedestre. Embora os construtores de estrada de antigamente não compreendessem os princípios da mecânica dos solos, souberam intuitivamente que, se fosse aplicada uma carga pesada ao solo estática ou dinamicamente, as suas características melhoravam e era possível construírem caminhos mecanicamente mais estáveis, e que cumprissem a sua função de traficabilidade.

Cada tipo de solo exige um equipamento diferente para sua melhor compactação. Como forma de descobrir qual equipamento usar, são criadas pistas experimentais, para testar a funcionalidade do equipamento, identificando qual o melhor a ser utilizado, e outros parâmetros que influem no processo, como espessura da camada solta, número de passadas, velocidade do equipamento, umidade, peso do lastro, entre outras. O professor Gil C. Paulo de Almeida, faz uso de tabelas em sua apostila para ilustrar os tipos de equipamentos para cada solo. Seguem abaixo:

Tabela 1 - Equipamentos - Apostila Construção de Estradas II (Prof. Gil Carvalho Paulo de Almeida)

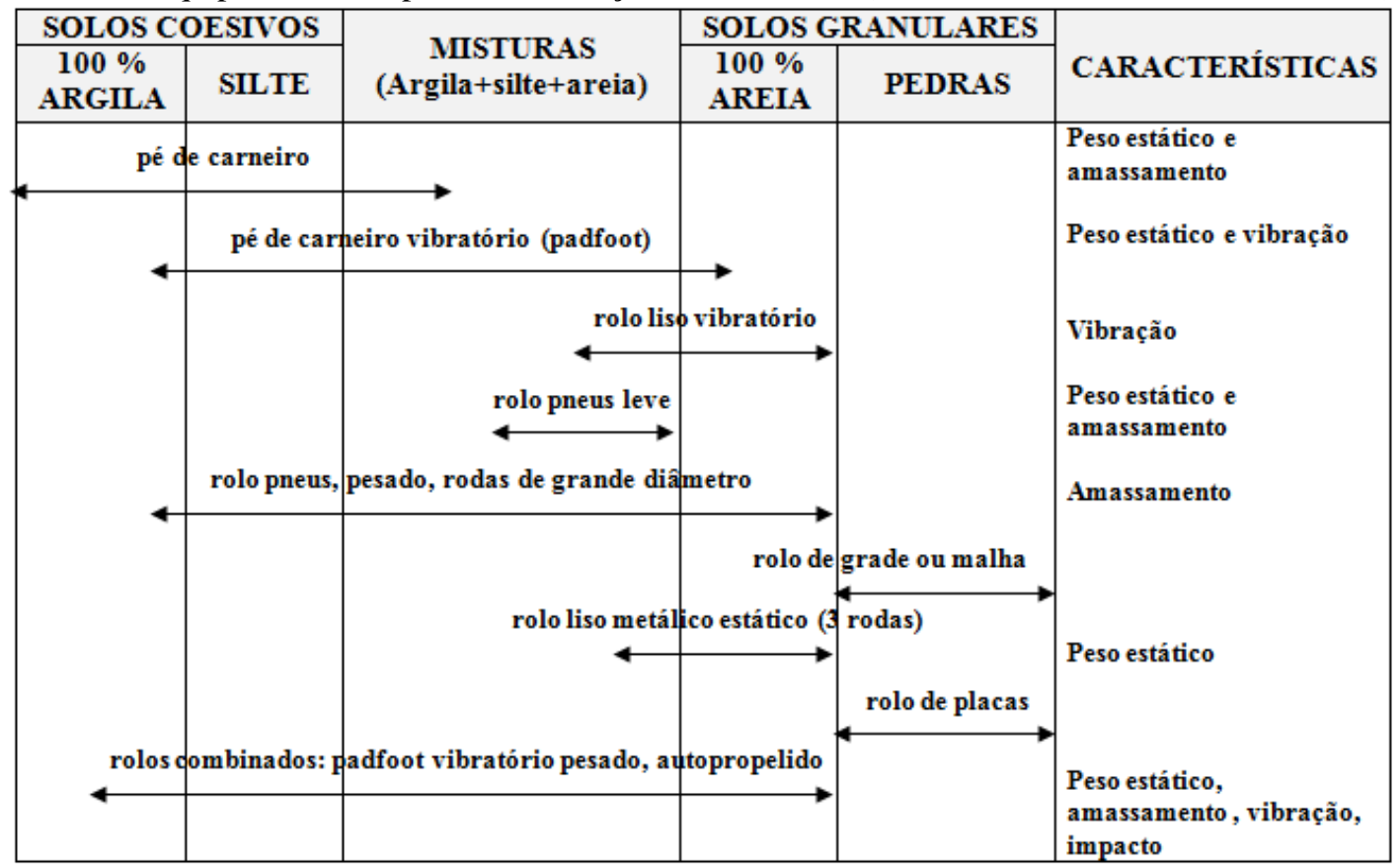


Tabela 2 - Tipos de Rolos - Apostila Construção de Estradas II (Prof. Gil Carvalho Paulo de Almeida)

Escolha do rolo compactador

\begin{tabular}{|c|c|c|c|c|}
\hline TIPO DE ROLO & $\begin{array}{l}\text { PESO MÁXIMO } \\
\text { (toneladas) }\end{array}$ & $\begin{array}{c}\text { ESPESSURA } \\
\text { MÁXIMA APÓS } \\
\text { COMPACTAC̣ÃO }\end{array}$ & $\begin{array}{c}\text { UNIFORMIDADE } \\
\text { DA CAMADA }\end{array}$ & TIPO DE SOLO \\
\hline $\begin{array}{c}\text { Pé de carneiro } \\
\text { estático }\end{array}$ & 20 & $40 \mathrm{~cm}$ & Boa & Argilas e siltes \\
\hline $\begin{array}{c}\text { Pé de carneiro } \\
\text { vibratório }\end{array}$ & 30 & $40 \mathrm{~cm}$ & Boa & $\begin{array}{l}\text { Misturas de areia } \\
\text { com silte e argila }\end{array}$ \\
\hline Pneumático leve & 15 & $15 \mathrm{~cm}$ & Boa & $\begin{array}{l}\text { Misturas de areia } \\
\text { com silte e argila }\end{array}$ \\
\hline Pneumático pesado & 35 & $35 \mathrm{~cm}$ & Muito boa & Praticamente todos \\
\hline $\begin{array}{c}\text { Vibratório com } \\
\text { rodas metálicas lisas }\end{array}$ & 30 & $50 \mathrm{~cm}$ & Muito boa & $\begin{array}{l}\text { Areias, cascalhos, } \\
\text { material granular }\end{array}$ \\
\hline $\begin{array}{l}\text { Liso metálico } \\
\text { estático, } 3 \text { rodas }\end{array}$ & 20 & $10 \mathrm{~cm}$ & Regular & $\begin{array}{c}\text { Materiais } \\
\text { granulares, brita }\end{array}$ \\
\hline $\begin{array}{c}\text { Rolo de } \\
\text { grade(malha) }\end{array}$ & 20 & $20 \mathrm{~cm}$ & Boa & $\begin{array}{c}\text { Materiais granulares } \\
\text { ou em blocos }\end{array}$ \\
\hline Combinados & 20 & $20 \mathrm{~cm}$ & Boa & Praticamente todos \\
\hline
\end{tabular}

Todo o processo de compactação de solos é bastante detalhado, e obrigatoriamente deve seguir as etapas adequadas de análises, testes e cálculos, em especial nos casos de construções e pavimentações de grande porte, e o trabalho das máquinas é indispensável.

\subsubsection{Controle de Compactação}

Métodos de controle de compactação também devem ser usados, isso é feito em duas etapas, como mostra os dados da Apostila do prof. Gil C. Paulo de Almeida:

- $\quad$ Determinação da umidade: O processo de Speedy Moisture Test, é o mais usado para a construção de estradas, necessita calibração por comparação com o método da estufa. Sendo necessário tomar cuidado com os erros de zeragem, temperaturas muito diferentes de $20^{\circ} \mathrm{C}$, etc.

De acordo com os dados do Manual do DER-SP (Capítulo 11), as operações de pulverização e umidecimento, serão iniciadas após a regularização de cotas e escarificação da superfície obtida, até a cota de quinze centímetros inferior a cota de projeto dos serviços acabados. A água deverá ser uniformemente distribuída ao longo do percurso da irrigadeira, e imediatamente após o inicio do umidecimento serão iniciadas as operações de homogenização da umidade em toda a espessura da camada, com a pulverimisturadora. Os teores de umidade obtidos serão controlados, e as operações de umidecimento e homogenização prosseguirão até que se obtenha a umidade que não seja diferente da ótima, correspondente à energia de compactação especificada, em mais de um ponto percentual. 


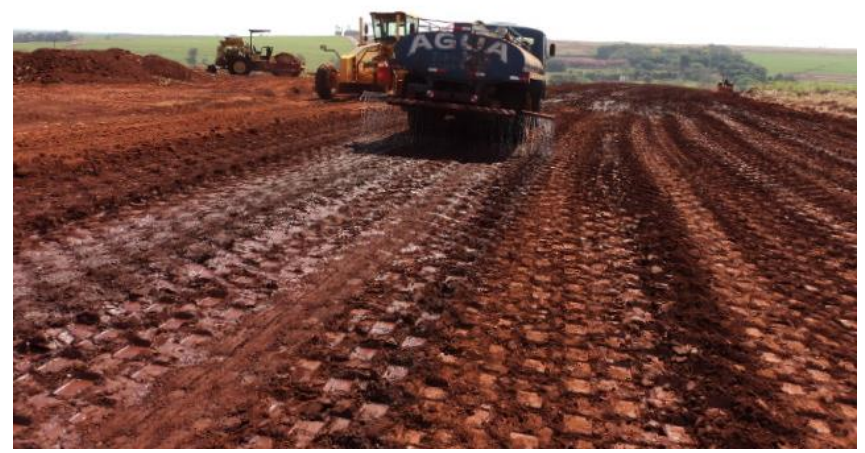

Figura 7 - Caminhão Irrigadeira

Fonte: Pavisolo Geotécnica e Pavimentação LTDA

- Determinação do Grau de Compactação $(\mathrm{G})$ : É depende da determinação da massa específica aparente "in situ". O método eleito é função do tipo de solo compactado. Os mais utilizados são o do óleo grosso, do frasco de areia e do cilindro de cravação. O primeiro, no caso de solos coesivos com pedregulho, o segundo em qualquer caso, o terceiro quando os solos apresentam coesão e não tem pedregulhos.

O grau de compactação é definido como sendo a razão entre o peso em volume obtido na obra e o peso em volume seco máximo determinado em laboratório, é calculado por equações.

Segundo as informações contidas no Manual de Normas do DER SP (capítulo 11), a compactação é feita somente após a obtenção do teor de umidade especificado, e utiliza rolos compressores compatíveis para cada tipo de solo. A compactação é feita progressivamente das bordas para o centro da pista, até a obtenção do grau especificado. Durante essa fase, serão efetuadas as verificações das cotas obtidas, de modo a assegurar que não sejam necessários novos aterros na fase de acabamento da superfície. O acabamento é efetuado com o auxilio de rolos liso e de pneus, sendo permitida a execução de novos cortes apenas, nessa etapa não se admite aterros. Em resumo essa fase se da pela remoção do material que ainda ficou solto, proveniente dos cortes para o acerto das cotas necessárias.

\subsubsection{Controle Geotécnico}

Ainda seguindo o Manual de Normas do DER SP (capítulo 11), temos as informações de controle geotécnico, que se divide em ensaios:

- Ensaios para o controle da execução: 1- Ensaio de caracterização, executados a razão de uma caracterização para cada 250 metros de pista, que deverão determinar o limite de liquidez (LL), limite de plasticidade (LP) e granulometria, pelos métodos DER M 4-61, M 5-61 e M 6-61, respectivamente; e 2- Ensaio para 
determinação do índice de suporte Califórnia (CBR), pelo método DER M 53-71, realizado a cada 500 metros de pista, onde o tipo de ensaio dependerá da porcentagem $(\mathrm{P})$ de material que passa pela peneira de $0,075 \mathrm{~mm}\left(\mathrm{n}^{\circ} 200\right)$, sendo o ensaio de equação [S.5 I.G], para porcentagem (em peso), menor ou igual á 35\%, e o ensaio de equação [S.5 N.g], para porcentagem maior que $35 \%$.

- Ensaios para fins de controle de execução e de recebimento dos serviços executados: 1- (quando for necessário, a critério da fiscalização) Ensaio de Compactação, pelo método DER M 13-71, com energia especificada, á razão de um ensaio para cada camada, e para cada 120 metros de pista, de modo a definir a massa especifica aparente seca máxima, e a umidade ótima; 2- Ensaio de determinação do teor de umidade, pelo método DER M 145-60, com umidímetro speedy ou similar, em cada camada, na razão de uma determinação para cada 100 metros de pista, e para cada faixa demarcada pela pulvorinisturadora no sentido transversal, em amostras representativas de toda a espessura da camada e colhidas após terminar as operações de umidecimento e homogenização, esse ensaio decide se é possível ou não iniciar a compactação de fato; 3 - Ensaio de Determinação da massa específica aparente seca, obtida "in situ", pelo processo do funil de areia e segundo o método DER M 23-57, em amostras retiradas na profundidade mínima de $75 \%$ da espessura da camada, á razão de uma determinação para cada 40 metros de camada compactada, inicialmente.

\subsubsection{Controle Geométrico}

O Controle Geométrico será exercido em duas etapas, sendo elas durante as operações construtivas, após compactação total do solo, com base nos piquetes de amarração do eixo e referência de cotas; e durante as operações de acabamento, com o auxilio de uma régua.

Após a total compactação do solo, o empreiteiro deverá conservar os serviços recebidos. A fiscalização irá julgar se necessário impor restrições ao trafego no local, e a partir desse momento, desde que todo serviço esteja de acordo com as normas pré-estabelecidas, a etapa de terraplenagem tem fim, dando lugar às próximas etapas da Construção Civil, como por exemplo, a pavimentação.

\section{Referências Bibliográficas}

BALBO, José Tadeu. Pavimentação Asfáltica - materiais, projeto e restauração. São Paulo. Editora Oficina de Texto. 2007.

DNER, Manual de Implantação Básica. 2a Edição. Rio de janeiro - RJ. 1996.

DER-SP, Manual de Normas Pavimentação, Capítulo 11, Estado de São Paulo.

Apostila Construção de Estradas II do Prof. Gil Carvalho Paulo de Almeida, da Faculdade de Engenharia da Universidade Federal de Juiz de Fora - MG.

Apostila Estabilização Granulométrica ou Mecânica do Prof. Engenheiro Douglas Fadul Villibor da Escola de Engenharia de São Carlos - SP. 1978. 
Apostila Terraplenagem da Prof ${ }^{a}$ Jisela Aparecida Santanna Grecco, da Escola de Engenharia da Universidade Federal de Minas Gerais. 